Published in final edited form as:

Int J Biochem Cell Biol. 2009 ; 41(1): 26-33. doi:10.1016/j.biocel.2008.05.028.

\title{
HIC1 (Hypermethylated in Cancer 1) epigenetic silencing in
}

\section{tumors}

\author{
Capucine Fleuriel, Majid Touka, Gaylor Boulay, Cateline Guérardel, Brian R Rood ${ }^{1}$, and \\ Dominique Leprince ${ }^{2}$
}

CNRS UMR 8161 «Institut de Biologie de LILLE», CNRS, Université de Lille 1 et de Lille 2, Institut PASTEUR de LILLE, 1 Rue Calmette, BP 447, 59017 LILLE Cedex, FRANCE

1Children's National Medical Center, Washington, DC., USA

\begin{abstract}
HICl (Hypermethylated In Cancer 1), as it name implied, was originally isolated as a new candidate tumor suppressor gene located at $17 \mathrm{p} 13.3$ because it resides in a $\mathrm{CpG}$ island that is hypermethylated in many types of human cancers. $\mathrm{HICl}$ encodes a transcription factor associating an $\mathrm{N}$-terminal BTB/ $\mathrm{POZ}$ domain to five $\mathrm{C}$-terminal Krüppel-like $\mathrm{C}_{2} \mathrm{H}_{2}$ zinc finger motifs. In this review, we will begin by providing an overview of the current knowledge on $\mathrm{HICl}$ function, mainly gained from in vitro studies, as a sequence-specific transcriptional repressor interacting with a still growing range of HDAC-dependent and HDAC-independent corepressor complexes. We will then summarize the studies that have demonstrated frequent hypermethylation changes or losses of heterozygosity of the HICl locus in human cancers. Next, we will review animal models which have firmly established $\mathrm{HICl}$ as a bona fide tumor suppressor gene epigenetically silenced and functionally cooperating notably with p53 within a complex HIC1-p53-SIRT1 regulatory loop. Finally, we will discuss how this epigenetic inactivation of $\mathrm{HICl}$ might "addict" cancer cells to altered survival and signaling pathways or to lineage-specific transcription factors during the early stages of tumorigenesis.
\end{abstract}

\section{Keywords}

HIC1; 17p13.3; transcriptional repression; p53; SIRT1

\section{Introduction}

For a long time cancer has been considered as a group of diseases driven by genetic modifications including chromosomal translocations, gene amplifications or point mutations in oncogenes or in tumor suppressor genes. However, it is now becoming increasingly clear that epigenetic changes, marked by DNA methylation and histone tail modifications, which convey heritable gene expression patterns, are also central to many human diseases including cancer.

DNA hypermethylation changes at the D17S5 locus in many cancers allowed the positional cloning of HICl (Hypermethylated In Cancer 1) as a candidate tumor suppressor located in

2Corresponding author. Tel.: 3332087 1119; Fax: 3332087 1111; E-mail: dominique.leprince@ibl.fr.

Publisher's Disclaimer: This is a PDF file of an unedited manuscript that has been accepted for publication. As a service to our customers we are providing this early version of the manuscript. The manuscript will undergo copyediting, typesetting, and review of the resulting proof before it is published in its final citable form. Please note that during the production process errors may be discovered which could affect the content, and all legal disclaimers that apply to the journal pertain. 
$17 \mathrm{p} 13.3$, a region frequently hypermethylated or deleted in many types of prevalent human tumors (Wales et al., 1995). HICl encodes a transcription factor with five Krüppel-like $\mathrm{C}_{2} \mathrm{H}_{2}$ zinc finger motifs (Wales et al., 1995) (Deltour et al., 1999) (Deltour et al., 2002) (Pinte et al., 2004b).

In this review, we will first provide an overview of the current understanding of $\mathrm{HIC} 1$ function as a sequence-specific transcriptional repressor. We will then describe the studies and animal models which unambiguously defined $\mathrm{HICl}$ as a tumor suppressor gene epigenetically silenced in many prevalent human cancers.

\section{HIC1: genomic organization}

From sequencing analyses of genomic clones and from functional assays, the exon-intron structures of the human and murine $\mathrm{HICl}$ genes appeared very similar with alternative first exons followed by a unique second exon, containing a coding region and a $3^{\prime}$ untranslated region (Carter et al., 2000) (Guerardel et al., 2001). The human HICl genomic region contains three promoters that give rise to different alternatively spliced transcripts. Exon 1a is noncoding and associated with the major G-C rich promoter, P1 whereas exon $\mathbf{1 b}$ is coding and associated with a minor TATA promoter called P0 (Figure 1) (Carter et al., 2000) (Guerardel et al., 2001). Exon 1c, as well as internally spliced exons called $\mathbf{1 d}$ and $\mathbf{1 e}$ are transcribed from a third upstream GC rich promoter, P2 conserved in the murine and rat genomes (Pinte et al., 2004a). However, transcripts initiated from this P2 promoter can only be detected by sensitive RT-PCR analyses. By contrast, $\mathbf{1 a}$ and $\mathbf{1 b}$ transcripts are detected by Northern blot in various normal tissues with a predominance for exon 1a transcripts and are upregulated by p53 and other p53 family members, notably TAp73 $\beta$ and $\Delta$ Np63 (Wales et al., 1995) (Guerardel et al., 2001) (Britschgi et al., 2006). The p53 responsive element in HIC1 is highly conserved in position (in the intron between exons $\mathbf{1 a}$ and $\mathbf{1 b}$ ) and in sequence among various species (Britschgi et al., 2006).

In addition, a novel, unspliced transcript variant, called $\mathbf{f}$, has been recently identified in normal leukocytes and in two human glioma cell lines, U87MG (wild-type p53) and U373MG (mutant p53) (Mondal et al., 2006). This unspliced transcript initiates from an alternate transcription start site localized 164bp downstream of the $\mathbf{1 b}$-specific promoter and could possibly encode a 22-amino acid polypeptide. In addition, this $\mathbf{f}$ transcript is not under the direct control of p53 but is induced in p53 wild-type cells grown in adverse conditions with a kinetic in opposite phase with the spliced transcripts. However, the biological significance of this $\mathbf{f}$ transcript has still to be elucidated although it has been suggested to regulate the level of HIC1 protein in cancer cells (Mondal et al., 2006).

\section{HIC1: functional aspects}

The $\mathrm{HIC1}$ protein is a sequence-specific transcriptional repressor containing three main functional domains (Figure 2): (i) the N-terminal BTB/POZ (which stands for Broad complex, Tramtrack and Bric à brac/Poxviruses and Zinc finger) domain of about 120 aminoacid is a dimerization domain known to play direct or indirect (through conformational effects) roles in protein-protein interactions. This domain is also an autonomous transcriptional repression domain (Albagli et al., 1995) (Stogios et al., 2005) (Kelly and Daniel, 2006); (ii) the C-terminal end contains five Krüppel-like $\mathrm{C}_{2} \mathrm{H}_{2}$ zinc fingers which bind a recently defined DNA sequence, termed the HiRE (HIC1 responsive element) (Pinte et al., 2004b) and a tail that displays no obvious functional domain but has been phylogenetically conserved (Deltour et al., 1998); (iii) a central region which is a second autonomous transcriptional repression domain (Deltour et al., 2002) (Stankovic-Valentin et al., 2006) (Stankovic-Valentin et al., 2007). 
Due to alternative splicing mechanisms, $\mathrm{HICl}$ could encode two highly related proteins. The major 1a-type transcripts direct the synthesis of a 714 amino acids protein encoded by the ORF in exon 2. Transcripts containing the conserved coding exon $\mathbf{1 b}$ could encode an alternative putative protein containing 19 additional $\mathrm{N}$-terminal amino acids ( 12 derived from exon $\mathbf{1 b}$ and 7 derived from $5^{\prime}$ sequences in exon $\mathbf{2}$ that are converted into coding sequences) (Figure 1) (Guerardel et al., 2001).

\subsection{The BTB/POZ domain}

The BTB/POZ domain is a highly conserved and widely distributed structural motif found mainly in transcription factors (Albagli et al., 1995). Crystal structures of severalhuman BTB/ $\mathrm{POZ}$ domains have demonstrated that this domain is a butterfly-shaped tightly intertwined obligate dimer with a conserved dimerization interface (Ahmad et al., 1998). BTB/POZ domains are protein-protein interaction domains and mediate homo-oligomerization, heterooligomerization as well as interactions with non-BTB/POZ proteins (Stogios et al., 2005). These properties are essential for the biological function of BTB/POZ-containing proteins. For example, the BCL6 BTB/POZ domain directly recruits nuclear corepressors SMRT, N-CoR or B-CoR/Histone deacetylase (HDACs) complexes in an exclusive manner. Co-crystal structure between the BCL6 BTB/POZ domain and a 17 amino-acid SMRT peptide have highlighted a lateral groove (Ahmad et al., 2003) that is bound competitively by B-CoR (Ghetu et al., 2008). Furthermore, the critical residues engaged in the interaction are not very well conserved, suggesting that distinct binding sites may exist and that protein-protein recognition modes could be specific to each $\mathrm{BTB} / \mathrm{POZ}$ domain. The $\mathrm{HIC} 1 \mathrm{BTB} / \mathrm{POZ}$ domain is also an autonomous transcriptional repression domains but is insensitive to trichostatin A (TSA), a specific inhibitor of class I and class II HDACs (Deltour et al., 1999; Deltour et al., 2001). It has been recently shown that HIC1 forms a transcriptional repression complex with the class III HDAC, SIRT1 and that this complex directly binds the SIRT1 promoter to repress its transcription (Chen et al., 2005). SIRT1 is a NAD-dependent deacetylase which is insensitive to TSA but sensitive to nicotinamide (NIA) (Saunders and Verdin, 2007). The HIC1 BTB/POZ domain interacts with SIRT1 (Chen et al., 2005) but its repressive activity in the context of a Gal4 chimera is not inhibited by NIA (our unpublished results).

Thus, the repression mechanisms inherent to the $\mathrm{HIC} 1 \mathrm{BTB} / \mathrm{POZ}$ domain have still to be deciphered.

\subsection{The HIC1 Central Region}

The HIC1 central region has not been subjected to a strong selection pressure except for 4 peptidic motifs perfectly conserved from human to zebrafish (Bertrand et al., 2004). One of them, GLDLSKK, is highly related to the canonical motif PxDLSxK/R found in proteins interacting with the co-repressor CtBP (C-terminal Binding Protein) (Chinnadurai, 2007). We have demonstrated that $\mathrm{HIC} 1$ interacts with the two related CtBP1 and CtBP2 corepressors through this conserved GLDLSKK motif thus extending the CtBP binding site (Deltour et al., 2002) (Stankovic-Valentin et al., 2006). Notably, mutation of the central leucine residue, Leu 225 in $\mathrm{HIC1}$, which is the only invariant residue in CtBP-interaction motifs, abolished the interaction between HIC1 and CtBP (Figure 2) (Stankovic-Valentin et al., 2006). As would be expected from the corepressor activity of CtBP, the L225A point mutation or deletion of the GLDLSKK motif impairs the repression potential of the HIC1 central region, but does not fully abolish it (Stankovic-Valentin et al., 2006). Thus, the HIC1 central region appears to be a second repression domain exhibiting both CtBP-dependent and CtBP-independent repression mechanisms, both of which are sensitive to TSA.

The second conserved motif is an YRWM/VK ${ }^{314} \mathrm{xEP}$ motif (Stankovic-Valentin et al., 2007) which contains a potential SUMOylation consensus site, $\psi \mathrm{KxE}$. SUMOylation is a reversible 
post-translational modification in which a member of the Small Ubiquitin-like Modifier (SUMO) family of proteins is covalently conjugated to lysine residues in target proteins (Verger et al., 2003) (Hay, 2005) (Geiss-Friedlander and Melchior, 2007). Unlike ubiquitination which generally marks proteins for rapid degradation, SUMOylation of nuclear proteins has very diverse effects on transcriptional activity ranging from regulation of DNAbinding activity, subcellular localization and assembly of multiprotein complexes. In the case of HIC1, SUMOylation of K314 does not affect its subnuclear localization and its interaction with CtBP, HDAC4 and SIRT1 but does positively regulate the transcriptional repression potential (Stankovic-Valentin et al., 2007).

Lysine residues can be targeted by several post-translational modifications including SUMOylation, acetylation, ubiquitination or methylation. The $\psi \mathrm{KxEP}$ motif in HIC1 with the Proline residue conserved from human to zebrafish is related to the G/SKxxP consensus motif for acetylation by $\mathrm{CBP} / \mathrm{P} 300$. Indeed, we have shown that $\mathrm{HIC} 1$ is acetylated on various Lysine residues including K314. Thus, the $\psi \mathrm{KxEP}$ motif is an acetylation/SUMOylation switch which is related to the $\psi \mathrm{KxEPxxSP}$, phosphorylation-regulated SUMOylation-acetylation switch motif (SAS) found in the major MEF2 isoforms (Shalizi et al., 2006). In both cases, the crosstalk between these two competitive post-translational modifications of Lysine residues is orchestrated by a new complex associating two distinct types of deacetylases, HDAC4 and SIRT1. Eventhough the precise mechanisms are not fully understood, these results identify HIC1 as a new target of the class III deacetylase SIRT1.

In conclusion, the $\mathrm{HIC} 1$ central region is essential for the transcriptional repression potential of HIC1. But, corepressors and complexes interacting with this region have still to be characterized.

\subsection{The Zinc finger DNA-binding domain and the HIC1 target genes}

The $\mathrm{C}$-terminal end contains a cluster of four conserved $\mathrm{C}_{2} \mathrm{H}_{2}$ zinc fingers (ZF2-5) which are separated by the typical 7-8 amino acid conserved $\mathrm{H} / \mathrm{C}$ links found in Krüppel-like Zinc fingers, making them likely to be involved in sequence-specific DNA binding. Using a combination of functional assays and in silico analyses, we have identified the sequence $5^{\prime}-\mathrm{C} / \mathrm{GNG}^{\mathrm{N}} / \mathrm{G} \mathrm{GGGCA} / \mathrm{C} / \mathrm{CC}-3^{\prime}$ as an optimal $\mathrm{HIC} 1$ binding site (HiRE for HIC1-responsive element) and validated by mutational analyses a GGCA core motif bound by Zinc fingers 3 and 4 (Figure 2) (Pinte et al., 2004b). In addition, HIC1 proteins contain a more distant and isolated upstream Zinc finger motif (ZF1) which is conserved but is unlikely to contribute to DNA-binding.

We have also shown that the full-length $\mathrm{HIC1}$ protein is modified with O-linked $N$ acetylglucosamine ( $O$-GlcNAc) (Lefebvre et al., 2004). This glycosylation is a dynamic modification of nuclear or cytoplasmic proteins by a single residue of $N$-acetylglucosamine on serine and threonine residues and can compete with phosphorylation (Guinez et al., 2005). Using deletion mutants, we have shown that most of the $O$-GlcNAc modifications of HIC1 occur in the DNA-binding domain although it does not affect its specific DNA-binding activity.

The full-length HIC1 protein is unable to bind to a single optimized site and this DNA-binding inhibition is clearly BTB/POZ-dependent. Whereas the HIC1 BTB/POZ domain impedes binding to a single site, it mediates strong cooperative binding to a probe containing multiple optimized sites (Pinte et al., 2004b).

The first bona fide HIC1 direct target gene, SIRT1, contains a cluster of two HiRE in the same orientation located at the $5^{\prime}$ end of the promoter (Chen et al., 2005). ChIP and ChIP upon ChIP assays demonstrated that $\mathrm{HIC} 1$ forms a transcriptional repression complex with the deacetylase SIRT1 to directly bind the SIRT1 promoter and repress its transcription. SIRT1 can also be 
regulated by $\mathrm{HIC} 1$ in response to acute metabolism changes by a complex between $\mathrm{HIC} 1$ and the redox sensor CtBP corepressor (Zhang et al., 2007).

The second HIC1 target gene, FGF-BPI (Fibroblast Growth Factor-Binding Protein 1) has been shown to play key roles in blood vessel development in the growing embryo as well as in tumor angiogenesis. This extracellular matrix bound protein enhances fibroblast growth factor (FGF) signaling which induces endothelial cell proliferation and smooth cell differentiation. TGF- $\beta$ represses $F G F-B P 1$ mRNA expression through its intermediates, the transcription factors Smad2 and Smad3. However, functional analyses of the FGF-BPI promoter using deletion constructs identify a region containing a HIC1 binding site, which could participate to the repression of $F G F-B P I$ by TGF- $\beta$ (Briones et al., 2006). This potential link between $\mathrm{HIC} 1$ and two pathways involved in angiogenesis is particularly interesting given HIC1's strong association with many human tumors.

Very recently, Atonal Homolog1 (Atoh1/Math1), a basic helix-loop-helix (bHLH) transcription factor expressed in and required for the proper development of various neural progenitor cells, notably including cerebellar granule cells has been identified as a direct transcriptional target of HIC1 through genome-wide profiling analysis of HICl-deficient medulloblastoma D425 cells infected with adenoviruses expressing HIC1 (Briggs et al., 2008). The proper expression of Atohl in the developing central nervous system relies on a $1.4 \mathrm{Kbp}$ downstream enhancer region that contains two adjacent HiRE in the same orientation, as observed in the SIRTI promoter (Chen et al., 2005). These two sites are bound by HIC1 as shown by chromatin immunoprecipitation experiments in normal mouse embryonic cerebella (Briggs et al., 2008).

Besides its direct target genes which remain largely to be identified, HIC1 could also bind to other transcription factors and "indirectly" repress transcription of target genes that do not contain HIC1 binding sites. HIC1 was shown to interact with TCF4, a major component of the Wnt signaling pathway, in a complex multidomain mode of interaction. As a consequence, TCF4 and $\beta$ catenin are recruited to discrete nuclear structures called HIC1 bodies and diverted from the Wnt-responsive promoters (Valenta et al., 2006). Thus, the intracellular amounts of $\mathrm{HIC} 1$ protein can modulate the transcriptional stimulation of genes regulated by canonical Wnt/ $\beta$ catenin signaling.

Further work will be required to determine if these $\mathrm{HIC} 1$ bodies can also sequester other transcription factors away from their DNA targets.

\section{Inactivation of $H I C 1$ is frequent in cancers}

From the beginning, the history of $\mathrm{HICl}$ has been directly linked to P53. Indeed, loss of heterozygosity (LOH) on the short arm of chromosome $17(17 \mathrm{p})$ is one of the most common genetic alterations in human cancers and allelic losses most often coincide with mutations in the TP53 gene at 17p13.1 (Ko and Prives, 1996). However, it became rapidly obvious that in breast and ovarian tumors, $17 \mathrm{p}$ allelic losses occur at high frequency in regions distal to TP53 and even in the absence of TP53 mutations. Consequently, these studies led to the proposal that one or more tumor suppressor genes whose loss of function is required for early tumorigenesis may reside in a region telomeric to TP53 (Cornelis et al., 1994) (Sakamoto et al., 1996) (Liscia et al., 1999). A good candidate region was 17p13.3 containing the VNTR (Variable Number of Tandem Repeats) microsatellite marker YNZ22/D17S5/D17S30 that exhibits frequent DNA hypermethylation in lung and colon cancer (Makos et al., 1992) as well as in neural (Makos et al., 1993a) (Rood et al., 2002) and renal tumors (Makos et al., 1993b). Indeed, DNA hypermethylation changes of the NotI restriction sites at the D17S5 locus in many cancers allowed the positional cloning and characterization by nucleotide sequencing of a new gene called HICl (Hypermethylated In Cancer 1) (Wales et al., 1995). HICl's role as a candidate tumor suppressor gene is supported by several observations: it is epigenetically 
silenced by promoter hypermethylation in many tumor cell lines as well as in primary colon and brain tumors; its enforced expression by stable transfection in various cancer cell lines results in a significant decrease in their clonogenic survival and its expression can be upregulated by p53 (Wales et al., 1995).

\subsection{HIC1 inactivation in solid tumors}

After this pioneering work, several groups have confirmed these observations using the methylation-sensitive restriction enzyme NotI and Southern blotting with D17S5 or HICl probe as well as more sensitive and informative assays such as methylation-specific PCR (MSP) and bisulfite sequencing. These studies have extended the epigenetic silencing of HICl to prostate cancers (Morton et al., 1996); non-small cell lung cancers (Eguchi et al., 1997) (Hayashi et al., 2001); breast cancers (Fujii et al., 1998); gastric and liver cancers (Kanai et al., 1998) (Kanai et al., 1999); esophageal cancers (Huang et al., 2000) (Eads et al., 2001) and human male non-seminomatous germ cell tumors (Koul et al., 2002). Epigenetic silencing of $\mathrm{HICl}$ has been also very frequently observed in the most common malignant brain tumor of childhood medulloblastoma (Rood et al., 2002) (Rathi et al., 2003) (Waha et al., 2003) and the glial malignancy, ependymoma (Waha et al., 2004).

$\mathrm{HICl}$ is thus epigenetically silenced in many types of common human cancers. However, some general conclusions can be drawn. First, loss of heterozygosity (LOH) is often associated and in fact preceded by DNA hypermethylation (Makos et al., 1993b) (Ahuja et al., 1997) (Kanai et al., 1999). For example, $\mathrm{HICl}$ is virtually completely methylated in 27 out of 39 breast cancer tissues tested (67\%) and $\mathrm{LOH}$ of the telomeric part of $17 \mathrm{p}$ where $\mathrm{HICl}$ is located, is observed in 22 out of these 27 cases with $\mathrm{HICl}$ hypermethylation (Fujii et al., 1998). Second, the level of $\mathrm{HICl}$ promoter hypermethylation is variable and a high density of methylation is associated with aggressiveness of the tumor and poor overall survival (Wales et al., 1995) (Nicoll et al., 2001) (Hayashi et al., 2001) (Rood et al., 2002) (Waha et al., 2004). Finally, dense hypermethylation of one $\mathrm{HICl}$ allele has also been detected in some normal tissues including kidney (Makos et al., 1993a), histologically normal prostate and benign hyperplasic (BPH) tissues (Morton et al., 1996), normal ductal breast tissues (Fujii et al., 1998) and in normal brain and cerebellum (Rood et al., 2002). This is in striking contrast with the lack of HICl hypermethylation in most normal tissues (Wales et al., 1995) and suggests that these tissues might be at higher risk for developing cancer since one copy of $\mathrm{HICl}$ is already constitutively inactivated.

There is some evidence from human tumor specimens to suggest that epigenetic $\mathrm{HICl}$ silencing events predispose tissues to tumorigenesis. In paired tumorous and non-tumorous tissues from patients with non-small cell lung cancer (NSCLC), HIC-1 was found to be methylated in 33\% and $31 \%$, respectively. Further, methylation occurred with a significantly greater incidence in tumorous and non-tumorous tissues from smokers compared to non-smokers (Eguchi et al., 1997). DNA methylation was inversely correlated with tumor cell differentiation and positively correlated with $\mathrm{LOH}$ at the same locus. These results support $\mathrm{HIC}-1$ methylation as a smokingrelated pre-cancerous event involved in the tumorigenesis of less differentiated NSCLC. In addition, methylation in the region of the tumor suppressor gene HIC-l increases across the histologic spectrum extending from normal liver tissues to the pre-cancerous conditions of chronic hepatitis and cirrhosis to hepatocellular carcinoma (Kanai et al., 1999). In colon cancer, DNA on chromosome arm 17p13.3 exhibits increasing methylation density from normal colonic mucosa to pre-cancerous colonic polyps to colon cancer (Makos et al., 1992).

\subsection{HIC1 inactivation in hematological malignancies}

Besides its implication in solid tumors, $\mathrm{HICl}$ is also a tumor suppressor gene epigenetically silenced in some leukemia. Indeed, $\mathrm{HICl}$ is not methylated in normal peripheral blood cells, 
in bone marrow cells or in purified CD34+ progenitor cells and only rarely methylated in acute leukemias at diagnosis (10\%) and in the chronic-phase of chronic myelogenous leukemia CML $(50 \%)$ (Issa et al., 1997a) (Issa et al., 1997b). By contrast, HICl is found methylated in virtually all recurrent acute lymphocytic leukemia and in the blast-crisis of all CML. HIC1

hypermethylation has thus been considered to be a late event in hematopoietic neoplasms (Issa et al., 1997a) (Issa et al., 1997b). Two others studies have detected a high level of methylation in acute myeloid leukemia by bisulfite sequencing, but in the central coding region of $\mathrm{HICl}$ (Melki et al., 1999b) (Melki et al., 1999a). A recent study has demonstrated that HICl expression is low in 128 patient samples of AML and in CD34+ progenitor cells as compared to terminally differentiated granulocytes (Britschgi et al., 2008). However, the HICl promoters are not methylated as shown by bisulfite sequencing or treatment with the demethylating agent 5-Aza-dC which induces $\mathrm{HIC} 1$ expression but less efficiently than the differentiation agent alltrans retinoic acid (ATRA) (Britschgi et al., 2008). Thus, these results suggest that $\mathrm{HICl}$ might play a role in granulocytic differentiation and that low expression of $\mathrm{HICl}$, which is not due to promoter hypermethylation, could contribute to leukemogenesis.

Finally, $\mathrm{HICl}$ has also been recently implicated as a tumor suppressor gene in a subset of diffuse large B-cell lymphomas (DLBCLs). Classically, hypermethylation of HICl promoter is accompanied by simultaneous deletion of the second allele in ca $90 \%$ of the cases (Stocklein et al., 2007).

\section{Mouse models of Hic1 and cancer}

The epigenetic silencing or deletion of $\mathrm{HICl}$ in numerous primary tumors and cell lines strongly suggested that it could be a new tumor suppressor gene. Unquestionable clues to the tumor suppressor function of $\mathrm{HICl}$ have come from the study of $\mathrm{Hicl}$ deficient mice developed in Dr Baylin's laboratory (Chen et al., 2003). Building on this work, two double heterozygote models have shown that Hicl can cooperate with p53 and Ptchl in tumorigenesis (Chen et al., 2004) (Briggs et al., 2008).

\subsection{Hic1+/- heterozygotes}

Whereas homozygous disruption of Hicl impairs development and results in embryonic and perinatal lethality (Carter et al., 2000), heterozygous Hicl+/- mice develop an age- and genderdependent spectrum of malignant tumors with a predominance of epithelial cancers in males (75\%) and lymphomas and sarcomas (80\%) in females (Chen et al., 2003). Overall, $44 \%$ of the malignant tumors were epithelial cancers in $\mathrm{Hicl}+/$ - mice. Such a high percentage is unusual when compared with the preponderance of lymphomas and sarcomas observed in other knockout models of tumor suppressor genes or in aged mice but is reminiscent of the cancer types seen in adult humans (DePinho, 2000). So far, these genders effects seen in mice have not been reported in human cancer: a female predominance has not been observed among HICl heterozygous diffuse large B-cell lymphoma patients (Stocklein et al., 2007). Another attribute is illustrated by the Dmp1 heterozygous knockout model. Dmpl is haplo-insufficient for tumor suppression and the wild-type Dmpl allele is retained and expressed in spontaneous tumors arising in Dmp 1+/- heterozygous mice (Inoue et al., 2001). By contrast, no Hicl expression has been detected in the Hic l+/- tumors (Chen et al., 2003). In fact, loss of function of the remaining $\mathrm{Hicl}$ allele in heterozygous mice is not due to gross chromosomal deletions but rather occurs only in association with hypermethylation of one of the two major alternative promoters of the gene as in human cancers. Bisulfite genomic sequencing of human tumor cell lines not expressing $\mathrm{HICl}$ have detected in most cases a dense methylation only of the $\mathbf{1 b}$ promoter although the most abundant $\mathrm{HICl}$ transcripts in the corresponding normal tissues are derived from the 1a promoter. In the Hicl +/- heterozygous mice, a dense methylation of the 1a but not the $1 \mathbf{b}$ promoter on the remaining allele is observed in the lymphomas and sarcomas arising mainly in females. Conversely, a dense methylation of the $\mathbf{1 b}$ promoter is found in the 
carcinomas and adenomas arising mainly in males (Chen et al., 2003). The transcription factor networks and the mechanisms underlying this complex tissue-, age- and sex-dependant epigenetic regulation of $\mathrm{HICl}$ are yet to be identified.

These results clearly demonstrate that loss of function of $\mathrm{Hicl}$ can lead to cancers. $\mathrm{HICl}$ was originally identified by virtue of its frequent epigenetic inactivation in tumors and so far point mutations inactivating $\mathrm{HICl}$ have not been reported. For example, a search for SSCP in the $\mathrm{HICl}$ coding sequence in 68 medulloblastomas only detected a single case of an in-frame deletion of 4 GGC codons in a Glycine-rich sequences located after the BTB/POZ domain with no effect on the downstream reading frame (Waha et al., 2003).

Thus, the case of $\mathrm{HICl}$ further illustrates that characterization of the "methylome", the complete set of DNA methylation modifications of a cell, is a potent tool for discovery of new tumor suppressor genes (Jones and Baylin, 2007).

\subsection{Tp53+/- and Hic1+/- cis or trans double heterozygotes}

Hicl and p53 are located on the same chromosome in humans (chromosome 17) and mice (chromosome 11). Two models of double heterozygous knockout mice with disruption of both genes either on the same chromosome (cis) or on separate chromosomes (trans) have been generated (Chen et al., 2004). The cis double heterozygotes have an accelerated tumorigenesis as compared to $p 53+/$ - mice and predominantly develop aggressive metastatic osteosarcomas, breast and ovarian tumors instead of soft tissues sarcomas. In these cis tumors, the remaining p53 and Hic 1 wild-type alleles are simultaneously deleted due to loss of the entire chromosome. By contrast, the trans Hicl+/- $553+/$ - mice have no acceleration of tumorigenesis as compared to $p 53+/-$ mice, albeit their tumors also develop in an age-dependant manner with a higher incidence of osteosarcomas. In the trans tumors, the remaining Hicl allele is retained and epigenetically silenced by hypermethylation while the $p 53$ allele undergoes interstitial deletion. The combination of these two events as compared to simultaneous deletion of the two genes could easily explain the earlier appearance and more severe phenotype observed in the cis animals (Chen et al., 2004). Thus, the epigenetically silenced gene Hicl cooperates with the mutated tumor suppressor gene $p 53$ in determining cancer prevalence, progression and spectrum.

\subsection{Ptch1+/- and Hic1+/- double heterozygotes}

Medulloblastoma, a childhood brain tumor arising from cerebellar granule cell precursors (GCPs) frequently displays inappropriate constitutive activation of the Hedgehog (Hh) signaling pathway as well as chromosome $17 \mathrm{p}$ deletion (Ferretti et al., 2005). The PATCHED (PTCH) transmembrane receptor, an inhibitor of the SMOOTHENED (SMO) coreceptor for Hedgehog $(\mathrm{Hh})$ is a tumor suppressor gene inactivated in sporadic medulloblastoma and Ptchl+/- heterozygotes spontaneously develop medulloblastomas at a frequency of 10-15\% (Goodrich et al., 1997). In addition, germline mutations in PATCHED result in the nevoid basal cell carcinoma syndrome (Gorlin syndrome) which is often associated with medulloblastoma. Whereas mutations in elements of the Hedgehog signaling pathway are found in less than $25 \%$ of sporadic medulloblastomas, deletion of chromosome $17 \mathrm{p}$ occurs in up to $50 \%$ of the cases and is frequently restricted to the $17 \mathrm{p} 13.1-13.3$ region containing several tumor suppressor genes including p53, REN, MNT and HICl (Ferretti et al., 2005). P53 is not frequently mutated in medulloblastomas (less than 10\%) but loss of function of $p 53$ significantly increases the frequency of medulloblastomas occurring in Ptchl+/- $p 53+/-$ animals as compared to Ptchl+/- heterozygotes (Wetmore et al., 2001). Similarly, a recent study revealed a four-fold increase in medulloblastomas incidence in Ptchl+/- Hicl+/- (19/45) as compared to their Ptchl+/- littermates (Briggs et al., 2008). Apart from this increased incidence, the time frame and the type of tumors did not vary between these two cohorts, in 


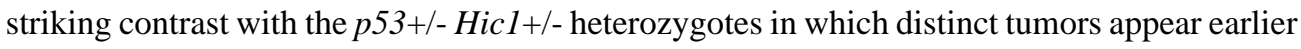
than in the $p 53+/-$ cohort (Chen et al., 2004).

Whereas Hicl is expressed during the differentiation of granule cell precursors, its expression (measured at mRNA and proteins levels) is markedly reduced in Ptchl+/- Hicl+/- and Ptchl +/- medulloblastomas (Briggs et al., 2008). In both cases, this is due to the methylation of the 1b promoter, as demonstrated by bisulfite sequencing. At the molecular level, Hicl does not play a key role in Hedgehog pathway regulation. Thus, its loss of function is not likely to directly participate in the activation of this pathway but could rather result in the overexpression of target genes ultimately leading to tumorigenesis. ATOH1, a transcription factor expressed in precursor granule cells and in medulloblastoma, activated by the Hh pathway and identified as a direct target of the HIC1-mediated transcriptional repression, nicely fulfills these criteria (Briggs et al., 2008). Moreover, siRNA-mediated knockdown of ATOHI dramatically reduces the viability of a cell line derived from a Ptchl+/- Hicl +/- medulloblastoma. According to these data, Briggs et al. proposed the following model (Briggs et al., 2008). In Ptchl+/heterozygotes, puffs of GCP-like progenitors persist in the external granule cell layer, forming a presumed precursor lesion. Since Hicl is hypermethylated in the Ptchl+l- Hicl+l- and Ptchl $+/$ - medulloblastomas, its epigenetic inactivation favored in the context of the Ptchl+/- Hicl $+/$ - double heterozygotes could be one of the next deficiencies accumulated in the Ptchl+/precursor lesion contributing to tumorigenesis (Briggs et al., 2008). The cooperation between these two tumor suppressors, the $\mathrm{HICl}$ transcriptional repressor and the Hh-receptor PATCHED1, is highly relevant to human medulloblastoma, in which deletion of the chromosomal $17 \mathrm{p}$ region would thus result in the loss of Hedgehog modulators such as REN (Di Marcotullio et al., 2004) and in the loss of regulators of lineage-specific transcription factors, as exemplified above by the HICl-ATOHI connection.

\section{HIC1: a cancer stem cell gene pre-marked for aberrant silencing in ES cells}

According to the cancer stem cell hypothesis which is now widely accepted, tumors contain and are driven by a minority cellular population which has retained key stem-cell properties including self-renewal, pluripotency and the ability to reinitiate the tumor mass containing the cellular heterogeneity observed in the original tumor (Jones and Baylin, 2007). Numerous studies have highlighted the key roles of epigenetic signatures in stem-cell identity (reviewed in (Spivakov and Fisher, 2007)). In pluripotent embryonic stem cells (ES), whereas pluripotency-associated transcription factors such as Nanog or Oct4 are expressed, the promoters of some developmental transcription factors are in a "bivalent state" with both activating (H3K9Ac and H3K4me) and repressive (H3K27me) epigenetic marks. Thus, these promoters are "poised" in a transcription-ready state which, depending on the developmental cues, can be tipped toward activation of tissue-specific genes or reversible silencing of genes involved in other developmental pathways. Indeed, in differentiated cells, the promoters of many non-transcribed genes have lost the activating marks and are enriched with the H3K27 trimethylated mark which is deposited by the Polycomb repressor complex 2 (PRC2) (Spivakov and Fisher, 2007).

Besides these genome-wide analyses, three studies in ES cells have determined the epigenetic status of restricted lists of genes defined as tumor suppressor genes frequently hypermethylated in cancer. Two of these studies have demonstrated that a very high percentage of genes specifically methylated in colon, breast and ovarian cancers are pre-marked with trimethylated H3K27 and other PRC2 components in ES cells (Lee et al., 2006; Schlesinger et al., 2007) (Widschwendter et al., 2007). The third study analyzed the malignant counterpart of ES cells, the embryonal teratocarcinoma (EC) (Ohm et al., 2007). EC are neoplastic embryonic cells, but in contrast with adult cancer cells they can retain properties of spontaneous differentiation and of lineage commitment in vivo and in vitro, albeit to a lesser extent than their normal ES 
counterparts. This study has further shown that embryonal carcinoma (EC) cells retain the bivalent marks typical of ES cells but display two additional repressive marks clearly linked to DNA-methylation, H3K9me2 and H3K9me3 (Ohm et al., 2007).

Collectively, these three studies strongly support the stem-cell origin of cancer and help to understand how normal stem cells with a transient transcription-ready state are converted into cancer progenitor cells with the permanent and heritable epigenetic silencing via DNA hypermethylation of some key genes probably due to aberrant crosstalk between the EZH2 component of PRC2 and DNA-methyl transferases (DNMTs). In fact, the loss of function of these genes could draw these progenitor cells from the normal differentiation pathway and lock them into a state of perpetual self renewal poised for tumorigenesis with the accumulation of further epigenetic or genetic events. Indeed, these cells could become dependent upon the pathways that are deregulated through the stable silencing of these genes. This dependency is termed "epigenetic sensitization" or "epigenetic cellular addiction" (Baylin and Ohm, 2006) and can favor the selection of cells that have additional cooperating mutations.

From these studies, $\mathrm{HICl}$ has been defined as a "stem cell gene" (a gene marked with at least two out of the three components SUZ12, EED and H3K27me3 in human ES cells) in colorectal cancer, ovarian cancer and CD34 positive hematopoietic progenitor cells (Widschwendter et al., 2007) but not in breast cancer. This exception may be due to its hemi-methylation in normal breast epithelium (Fujii et al., 1998). In addition, HICl is unmethylated in human ES cells and partially or fully methylated in two embryonal carcinomas cell lines, Tera-1 and Tera-2 respectively (Ohm et al., 2007).

Thus, in early tumorigenesis, epigenetic inactivation of $\mathrm{HICl}$ could induce an increase in SIRT1 deacetylase activity. The resulting deacetylation of P53 impairs its function leading to a defective apoptotic response to DNA-damage and a reduced ability to transactivate its target genes including HICl (Chen et al., 2005). This HIC1-SIRT1-P53 regulatory loop is an essential pathway through which $\mathrm{HICl}$ may function as a tumor suppressor gene and cooperate with P53, as shown by the double heterozygote model. SIRT1 can deacetylate not only P53 but also many other target proteins essential for normal homeostasis. Thus, epigenetic silencing of HICl can have both P53-dependent and P53-independent effects.

Moreover, $\mathrm{HICl}$ can also interfere with several other essential signaling pathways. For example, in normal conditions, HIC1 sequesters TCF4, a key transcriptional factor to which converges Wnt signaling, into nuclear substructures called "HIC1 nuclear bodies" and thus divert TCF4 from its transcriptional targets (Valenta et al., 2006). Loss of $\mathrm{HICl}$ expression in early tumorigenesis results in an increase of TCF4-mediated target gene expression and thus "addicts" the cells to an activated Wnt/ßcatenin signaling pathway.

A similar situation occurs through the direct transcriptional regulation of ATOH1, a transcriptional relay of the Hedgehog signaling pathway as detailed above (Briggs et al., 2008).

\section{Conclusions and future directions for research}

Thirteen years after its discovery by Dr Baylin's laboratory, $\mathrm{HICl}$ is now well-recognized as a tumor suppressor gene modulating p53-dependent apoptotic DNA damage responses through direct binding to the SIRT1 promoter; cooperating with Patched, an inhibitor of the Hedgehog pathway to induce medulloblastomas and able to modulate the Wnt pathway.

Despite this significant progress, many basic questions remain unresolved. First, an incomplete picture exists for the mechanisms of transcriptional regulation by HIC1. Second and more importantly, the list of characterized target genes appears to be very short considering the large 
numbers of potential physiological roles of $\mathrm{HICl}$. A better knowledge of these targets genes would also help to decipher the potentially numerous signaling pathways that could be deregulated through epigenetic inactivation of $\mathrm{HICl}$.

$\mathrm{HICl}$ is another example of a tumor suppressor gene silenced in cancer in association with promoter hypermethylation. As such, $\mathrm{HICl}$ could by itself be a new target for epigenetic therapies trough the combined use of pharmacologic DNA methyltransferase inhibitors and histone deacetylase inhibitors. Moreover, the identification of genes directly regulated by HIC1 warrants a more in-depth investigation due to their potential use as therapeutic targets. For example, cambinol, a compound that inhibits the NAD-dependent deacetylase activity of SIRT1 induces apoptosis of xenograft tumors in vivo derived from Burkitt's lymphomas overexpressing BCL-6, a transcription factor essential for B-cell fate and differentiation and deacetylated by SIRT1 (Heltweg et al., 2006). It would be interesting to determine if cambinol could also trigger apoptosis in tumors with loss of $\mathrm{HICl}$.

Further characterizing $\mathrm{HICl}$ function and its direct transcriptional targets would not only help to understand its role as a tumor suppressor gene and provide new insights into epigenetics and transcriptional repression in general but would also open new therapeutic approaches to major human cancers.

\section{Acknowledgements}

This review is dedicated to the memory of Christian Lagrou and Jean Coll.

CF and GB were supported by predoctoral fellowships from the Ministère de l'Education Nationale et de la Recherche and from CNRS/Région Nord-Pas de Calais respectively. MT was supported by a post-doctoral fellowship from Association for International Cancer Research (AICR). Our work was supported by funds from CNRS, PASTEUR Institute of Lille, Ligue contre le Cancer (Comité Régional du Septentrion), ARC (Association pour la Recherche contre le Cancer, Grant $\mathrm{N}^{\circ}$ 3983) and Association for International Cancer Research (AICR). BR is supported by NINDS, NIH grant \#1K08NS051477.

\section{References}

Ahmad KF, Engel CK, Prive GG. Crystal structure of the BTB domain from PLZF. Proc Natl Acad Sci U S A 1998;95:12123-12128. [PubMed: 9770450]

Ahmad KF, Melnick A, Lax S, Bouchard D, Liu J, Kiang CL, et al. Mechanism of SMRT corepressor recruitment by the BCL6 BTB domain. Mol Cell 2003;12:1551-1564. [PubMed: 14690607]

Ahuja N, Mohan AL, Li Q, Stolker JM, Herman JG, Hamilton SR, et al. Association between CpG island methylation and microsatellite instability in colorectal cancer. Cancer Res 1997;57:3370-3374. [PubMed: 9269998]

Albagli O, Dhordain P, Deweindt C, Lecocq G, Leprince D. The BTB/POZ domain: a new protein-protein interaction motif common to DNA- and actin-binding proteins. Cell Growth Differ 1995;6:1193-1198. [PubMed: 8519696]

Baylin SB, Ohm JE. Epigenetic gene silencing in cancer - a mechanism for early oncogenic pathway addiction? Nat Rev Cancer 2006;6:107-116. [PubMed: 16491070]

Bertrand S, Pinte S, Stankovic-Valentin N, Deltour-Balerdi S, Guerardel C, Begue A, et al. Identification and developmental expression of the zebrafish orthologue of the tumor suppressor gene HIC1. Biochim Biophys Acta 2004;1678:57-66. [PubMed: 15093138]

Briggs KJ, Corcoran-Schwartz IM, Zhang W, Harcke T, Devereux WL, Baylin SB, et al. Cooperation between the Hic1 and Ptch1 tumor suppressors in medulloblastoma. Genes Dev 2008;22:770-785. [PubMed: 18347096]

Briones VR, Chen S, Riegel AT, Lechleider RJ. Mechanism of fibroblast growth factor-binding protein 1 repression by TGF-beta. Biochem Biophys Res Commun 2006;345:595-601. [PubMed: 16690027] 
Britschgi C, Jenal M, Rizzi M, Mueller BU, Torbett BE, Andres AC, et al. HIC1 tumour suppressor gene is suppressed in acute myeloid leukaemia and induced during granulocytic differentiation. $\mathrm{Br} \mathrm{J}$ Haematol 2008;141:179-187. [PubMed: 18318772]

Britschgi C, Rizzi M, Grob TJ, Tschan MP, Hugli B, Reddy VA, et al. Identification of the p53 familyresponsive element in the promoter region of the tumor suppressor gene hypermethylated in cancer 1. Oncogene 2006;25:2030-2039. [PubMed: 16301995]

Carter MG, Johns MA, Zeng X, Zhou L, Zink MC, Mankowski JL, et al. Mice deficient in the candidate tumor suppressor gene Hic1 exhibit developmental defects of structures affected in the Miller-Dieker syndrome. Hum Mol Genet 2000;9:413-419. [PubMed: 10655551]

Chen W, Cooper TK, Zahnow CA, Overholtzer M, Zhao Z, Ladanyi M, et al. Epigenetic and genetic loss of Hic1 function accentuates the role of p53 in tumorigenesis. Cancer Cell 2004;6:387-398. [PubMed: 15488761]

Chen WY, Wang DH, Yen RC, Luo J, Gu W, Baylin SB. Tumor suppressor HIC1 directly regulates SIRT1 to modulate p53-dependent DNA-damage responses. Cell 2005;123:437-448. [PubMed: 16269335]

Chen WY, Zeng X, Carter MG, Morrell CN, Chiu Yen RW, Esteller M, et al. Heterozygous disruption of Hic1 predisposes mice to a gender-dependent spectrum of malignant tumors. Nat Genet 2003;33:197-202. [PubMed: 12539045]

Chinnadurai G. Transcriptional regulation by C-terminal binding proteins. Int J Biochem Cell Biol. 2007

Cornelis RS, van Vliet M, Vos CB, Cleton-Jansen AM, van de Vijver MJ, Peterse JL, et al. Evidence for a gene on 17p13.3, distal to TP53, as a target for allele loss in breast tumors without p53 mutations. Cancer Res 1994;54:4200-4206. [PubMed: 8033152]

Deltour S, Guerardel C, Leprince D. Recruitment of SMRT/N-CoR-mSin3A-HDAC-repressing complexes is not a general mechanism for BTB/POZ transcriptional repressors: the case of HIC-1 and gammaFBP-B. Proc Natl Acad Sci U S A 1999;96:14831-14836. [PubMed: 10611298]

Deltour S, Guerardel C, Stehelin D, Leprince D. The carboxy-terminal end of the candidate tumor suppressor gene HIC-1 is phylogenetically conserved. Biochim Biophys Acta 1998;1443:230-232. [PubMed: 9838134]

Deltour S, Pinte S, Guerardel C, Wasylyk B, Leprince D. The human candidate tumor suppressor gene HIC1 recruits CtBP through a degenerate GLDLSKK motif. Mol Cell Biol 2002;22:4890-4901. [PubMed: 12052894]

DePinho RA. The age of cancer. Nature 2000;408:248-254. [PubMed: 11089982]

Di Marcotullio L, Ferretti E, De Smaele E, Argenti B, Mincione C, Zazzeroni F, et al. REN(KCTD11) is a suppressor of Hedgehog signaling and is deleted in human medulloblastoma. Proc Natl Acad Sci U S A 2004;101:10833-10838. [PubMed: 15249678]

Eads CA, Lord RV, Wickramasinghe K, Long TI, Kurumboor SK, Bernstein L, et al. Epigenetic patterns in the progression of esophageal adenocarcinoma. Cancer Res 2001;61:3410-3418. [PubMed: 11309301]

Eguchi K, Kanai Y, Kobayashi K, Hirohashi S. DNA hypermethylation at the D17S5 locus in non-small cell lung cancers: its association with smoking history. Cancer Res 1997;57:4913-4915. [PubMed: 9354457]

Ferretti E, De Smaele E, Di Marcotullio L, Screpanti I, Gulino A. Hedgehog checkpoints in medulloblastoma: the chromosome 17p deletion paradigm. Trends Mol Med 2005;11:537-545. [PubMed: 16290230]

Fujii H, Biel MA, Zhou W, Weitzman SA, Baylin SB, Gabrielson E. Methylation of the HIC-1 candidate tumor suppressor gene in human breast cancer. Oncogene 1998;16:2159-2164. [PubMed: 9572497]

Geiss-Friedlander R, Melchior F. Concepts in sumoylation: a decade on. Nat Rev Mol Cell Biol 2007;8:947-956. [PubMed: 18000527]

Ghetu AF, Corcoran CM, Cerchietti L, Bardwell VJ, Melnick A, Prive GG. Structure of a BCOR corepressor peptide in complex with the BCL6 BTB domain dimer. Mol Cell 2008;29:384-391. [PubMed: 18280243]

Goodrich LV, Milenkovic L, Higgins KM, Scott MP. Altered neural cell fates and medulloblastoma in mouse patched mutants. Science 1997;277:1109-1113. [PubMed: 9262482] 
Guerardel C, Deltour S, Pinte S, Monte D, Begue A, Godwin AK, et al. Identification in the human candidate tumor suppressor gene HIC-1 of a new major alternative TATA-less promoter positively regulated by p53. J Biol Chem 2001;276:3078-3089. [PubMed: 11073960]

Guinez C, Morelle W, Michalski JC, Lefebvre T. O-GlcNAc glycosylation: a signal for the nuclear transport of cytosolic proteins? Int J Biochem Cell Biol 2005;37:765-774. [PubMed: 15694836]

Hay RT. SUMO: a history of modification. Mol Cell 2005;18:1-12. [PubMed: 15808504]

Hayashi M, Tokuchi Y, Hashimoto T, Hayashi S, Nishida K, Ishikawa Y, et al. Reduced HIC-1 gene expression in non-small cell lung cancer and its clinical significance. Anticancer Res 2001;21:535540. [PubMed: 11299800]

Heltweg B, Gatbonton T, Schuler AD, Posakony J, Li H, Goehle S, et al. Antitumor activity of a smallmolecule inhibitor of human silent information regulator 2 enzymes. Cancer Res 2006;66:43684377. [PubMed: 16618762]

Huang J, Hu N, Goldstein AM, Emmert-Buck MR, Tang ZZ, Roth MJ, et al. High frequency allelic loss on chromosome 17p13.3-p11.1 in esophageal squamous cell carcinomas from a high incidence area in northern China. Carcinogenesis 2000;21:2019-2026. [PubMed: 11062163]

Inoue K, Zindy F, Randle DH, Rehg JE, Sherr CJ. Dmp1 is haplo-insufficient for tumor suppression and modifies the frequencies of Arf and p53 mutations in Myc-induced lymphomas. Genes Dev 2001;15:2934-2939. [PubMed: 11711428]

Issa JP, Baylin SB, Herman JG. DNA methylation changes in hematologic malignancies: biologic and clinical implications. Leukemia 1997a;11 Suppl 1:S7-11. [PubMed: 9130685]

Issa JP, Zehnbauer BA, Kaufmann SH, Biel MA, Baylin SB. HIC1 hypermethylation is a late event in hematopoietic neoplasms. Cancer Res 1997b;57:1678-1681. [PubMed: 9135007]

Jones PA, Baylin SB. The epigenomics of cancer. Cell 2007;128:683-692. [PubMed: 17320506]

Kanai Y, Hui AM, Sun L, Ushijima S, Sakamoto M, Tsuda H, et al. DNA hypermethylation at the D17S5 locus and reduced HIC-1 mRNA expression are associated with hepatocarcinogenesis. Hepatology 1999;29:703-709. [PubMed: 10051471]

Kanai Y, Ushijima S, Ochiai A, Eguchi K, Hui A, Hirohashi S. DNA hypermethylation at the D17S5 locus is associated with gastric carcinogenesis. Cancer Lett 1998;122:135-141. [PubMed: 9464502]

Kelly KF, Daniel JM. POZ for effect--POZ-ZF transcription factors in cancer and development. Trends Cell Biol 2006;16:578-587. [PubMed: 16996269]

Ko LJ, Prives C. p53: puzzle and paradigm. Genes Dev 1996;10:1054-1072. [PubMed: 8654922]

Koul S, Houldsworth J, Mansukhani MM, Donadio A, McKiernan JM, Reuter VE, et al. Characteristic promoter hypermethylation signatures in male germ cell tumors. Mol Cancer 2002;1:8. [PubMed: 12495446]

Lee TI, Jenner RG, Boyer LA, Guenther MG, Levine SS, Kumar RM, et al. Control of developmental regulators by Polycomb in human embryonic stem cells. Cell 2006;125:301-313. [PubMed: 16630818]

Lefebvre T, Pinte S, Guerardel C, Deltour S, Martin-Soudant N, Slomianny MC, et al. The tumor suppressor HIC1 (hypermethylated in cancer 1) is O-GlcNAc glycosylated. Eur J Biochem 2004;271:3843-3854. [PubMed: 15373830]

Liscia DS, Morizio R, Venesio T, Palenzona C, Donadio M, Callahan R. Prognostic significance of loss of heterozygosity at loci on chromosome 17 p13.3-ter in sporadic breast cancer is evidence for a putative tumour suppressor gene. Br J Cancer 1999;80:821-826. [PubMed: 10360661]

Makos M, Nelkin BD, Chazin VR, Cavenee WK, Brodeur GM, Baylin SB. DNA hypermethylation is associated with 17p allelic loss in neural tumors. Cancer Res 1993a;53:2715-2718. [PubMed: 8389241]

Makos M, Nelkin BD, Lerman MI, Latif F, Zbar B, Baylin SB. Distinct hypermethylation patterns occur at altered chromosome loci in human lung and colon cancer. Proc Natl Acad Sci U S A 1992;89:19291933. [PubMed: 1347428]

Makos M, Nelkin BD, Reiter RE, Gnarra JR, Brooks J, Isaacs W, et al. Regional DNA hypermethylation at D17S5 precedes 17p structural changes in the progression of renal tumors. Cancer Res 1993b; 53:2719-2722. [PubMed: 8504410] 
Melki JR, Vincent PC, Clark SJ. Cancer-specific region of hypermethylation identified within the HIC1 putative tumour suppressor gene in acute myeloid leukaemia. Leukemia 1999a;13:877-883. [PubMed: 10360376]

Melki JR, Vincent PC, Clark SJ. Concurrent DNA hypermethylation of multiple genes in acute myeloid leukemia. Cancer Res 1999b;59:3730-3740. [PubMed: 10446989]

Mondal AM, Chinnadurai S, Datta K, Chauhan SS, Sinha S, Chattopadhyay P. Identification and functional characterization of a novel unspliced transcript variant of HIC-1 in human cancer cells exposed to adverse growth conditions. Cancer Res 2006;66:10466-10477. [PubMed: 17079468]

Morton RA Jr, Watkins JJ, Bova GS, Wales MM, Baylin SB, Isaacs WB. Hypermethylation of chromosome 17P locus D17S5 in human prostate tissue. J Urol 1996;156:512-516. [PubMed: 8683727]

Nicoll G, Crichton DN, McDowell HE, Kernohan N, Hupp TR, Thompson AM. Expression of the Hypermethylated in Cancer gene (HIC-1) is associated with good outcome in human breast cancer. Br J Cancer 2001;85:1878-1882. [PubMed: 11747329]

Ohm JE, McGarvey KM, Yu X, Cheng L, Schuebel KE, Cope L, et al. A stem cell-like chromatin pattern may predispose tumor suppressor genes to DNA hypermethylation and heritable silencing. Nat Genet 2007;39:237-242. [PubMed: 17211412]

Pinte S, Guerardel C, Deltour-Balerdi S, Godwin AK, Leprince D. Identification of a second G-C-rich promoter conserved in the human, murine and rat tumor suppressor genes HIC1. Oncogene 2004a; 23:4023-4031. [PubMed: 15007385]

Pinte S, Stankovic-Valentin N, Deltour S, Rood BR, Guerardel C, Leprince D. The tumor suppressor gene HIC1 (hypermethylated in cancer 1) is a sequence-specific transcriptional repressor: definition of its consensus binding sequence and analysis of its DNA binding and repressive properties. J Biol Chem 2004b;279:38313-38324. [PubMed: 15231840]

Rathi A, Virmani AK, Harada K, Timmons CF, Miyajima K, Hay RJ, et al. Aberrant methylation of the HIC1 promoter is a frequent event in specific pediatric neoplasms. Clin Cancer Res 2003;9:36743678. [PubMed: 14506157]

Rood BR, Zhang H, Weitman DM, Cogen PH. Hypermethylation of HIC-1 and 17p allelic loss in medulloblastoma. Cancer Res 2002;62:3794-3797. [PubMed: 12097291]

Sakamoto T, Nomura N, Mori H, Wake N. Poor correlation with loss of heterozygosity on chromosome 17 and p53 mutations in ovarian cancers. Gynecol Oncol 1996;63:173-179. [PubMed: 8910623]

Saunders LR, Verdin E. Sirtuins: critical regulators at the crossroads between cancer and aging. Oncogene 2007;26:5489-5504. [PubMed: 17694089]

Schlesinger Y, Straussman R, Keshet I, Farkash S, Hecht M, Zimmerman J, et al. Polycomb-mediated methylation on Lys27 of histone $\mathrm{H} 3$ pre-marks genes for de novo methylation in cancer. Nat Genet 2007;39:232-236. [PubMed: 17200670]

Shalizi A, Gaudilliere B, Yuan Z, Stegmuller J, Shirogane T, Ge Q, et al. A calcium-regulated MEF2 sumoylation switch controls postsynaptic differentiation. Science 2006;311:1012-1017. [PubMed: 16484498]

Spivakov M, Fisher AG. Epigenetic signatures of stem-cell identity. Nat Rev Genet 2007;8:263-271. [PubMed: 17363975]

Stankovic-Valentin N, Deltour S, Seeler J, Pinte S, Vergoten G, Guerardel C, et al. An acetylation/ deacetylation-SUMOylation switch through a phylogenetically conserved psiKXEP motif in the tumor suppressor HIC1 regulates transcriptional repression activity. Mol Cell Biol 2007;27:26612675. [PubMed: 17283066]

Stankovic-Valentin N, Verger A, Deltour-Balerdi S, Quinlan KG, Crossley M, Leprince D. A L225A substitution in the human tumour suppressor $\mathrm{HIC1}$ abolishes its interaction with the corepressor CtBP. Febs J 2006;273:2879-2890. [PubMed: 16762039]

Stocklein H, Smardova J, Macak J, Katzenberger T, Holler S, Wessendorf S, et al. Detailed mapping of chromosome $17 \mathrm{p}$ deletions reveals $\mathrm{HIC1}$ as a novel tumor suppressor gene candidate telomeric to TP53 in diffuse large B-cell lymphoma. Oncogene 2007;27:2613-2625. [PubMed: 17982487]

Stogios PJ, Downs GS, Jauhal JJ, Nandra SK, Prive GG. Sequence and structural analysis of BTB domain proteins. Genome Biol 2005;6:R82. [PubMed: 16207353] 
Valenta T, Lukas J, Doubravska L, Fafilek B, Korinek V. HIC1 attenuates Wnt signaling by recruitment of TCF-4 and beta-catenin to the nuclear bodies. Embo J 2006;25:2326-2337. [PubMed: 16724116]

Verger A, Perdomo J, Crossley M. Modification with SUMO. A role in transcriptional regulation. EMBO Rep 2003;4:137-142. [PubMed: 12612601]

Waha A, Koch A, Hartmann W, Mack H, Schramm J, Sorensen N, et al. Analysis of HIC-1 methylation and transcription in human ependymomas. Int J Cancer 2004;110:542-549. [PubMed: 15122586]

Waha A, Waha A, Koch A, Meyer-Puttlitz B, Weggen S, Sorensen N, et al. Epigenetic silencing of the HIC-1 gene in human medulloblastomas. J Neuropathol Exp Neurol 2003;62:1192-1201. [PubMed: 14656076]

Wales MM, Biel MA, el Deiry W, Nelkin BD, Issa JP, Cavenee WK, et al. p53 activates expression of HIC-1, a new candidate tumour suppressor gene on 17p13.3. Nat Med 1995;1:570-577. [PubMed: 7585125]

Wetmore C, Eberhart DE, Curran T. Loss of p53 but not ARF accelerates medulloblastoma in mice heterozygous for patched. Cancer Res 2001;61:513-516. [PubMed: 11212243]

Widschwendter M, Fiegl H, Egle D, Mueller-Holzner E, Spizzo G, Marth C, et al. Epigenetic stem cell signature in cancer. Nat Genet 2007;39:157-158. [PubMed: 17200673]

Zhang Q, Wang SY, Fleuriel C, Leprince D, Rocheleau JV, Piston DW, et al. Metabolic regulation of SIRT1 transcription via a HIC1:CtBP corepressor complex. Proc Natl Acad Sci U S A 2007;104:829833. [PubMed: 17213307] 


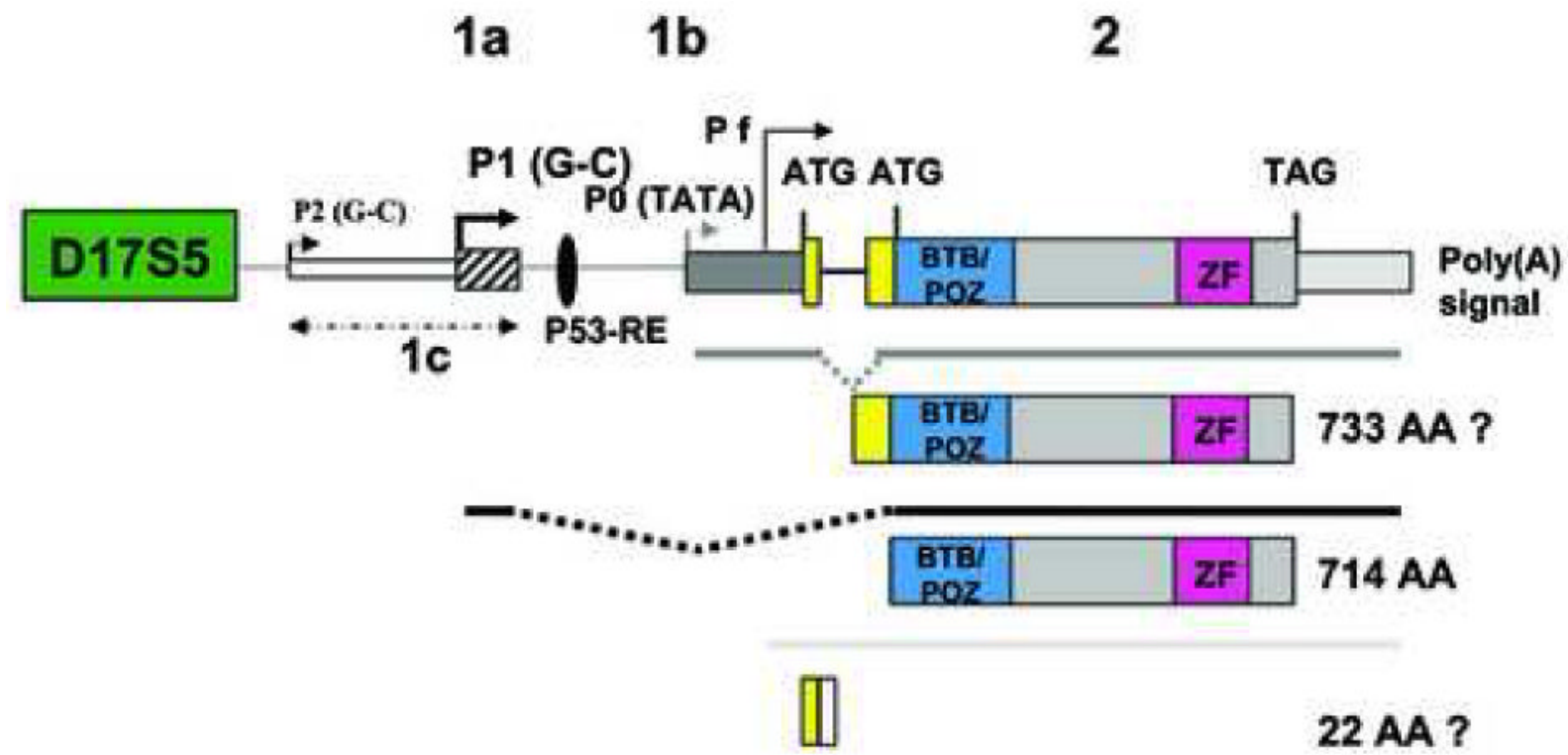

Figure 1. Genomic organization of the human HIC1 locus

The structure of the human HICl locus as derived from several studies is schematically drawn (Wales et al., 1995) (Guerardel et al., 2001). A similar organization is found in mice (Guerardel et al., 2001) (Carter et al., 2000). The two major promoters, called P1 and P0 and the minor P2 promoter generating $\mathrm{HIC} 1$ transcripts with heterogeneous $5^{\prime}$ ends are represented (Guerardel et al., 2001; Pinte et al., 2004a). For clarity, only the major types 1a and 1b, but not the minor 1c, $1 d$ and 1e transcripts have been shown below the human $\mathrm{HICl}$ genomic locus (Pinte et al., 2004a). In addition, the type 1a transcripts are by far the most abundant HIC1 transcripts. In human, only the $\mathbf{1 b}$ exon contains an ATG codon in-frame with the ATG initiation codon located in exon $\mathbf{2}$. It should be noted however that the existence of this 733 amino acid protein deduced from computer analyses has never been firmly established, through immunodetection with specific antibodies.

Recently, RT-PCR analyses have identified an unspliced transcript, called 1f initiated at an alternative promoter within exon $\mathbf{1 b}$. This transcript could potentially encode a short 22 aminoacid polypeptide initiated at the ATG codon of exon $\mathbf{1 b}$ and terminated by a stop codon in the intron (Mondal et al., 2006). The p53 binding site involved in the direct regulation of HICl transcription (Wales et al., 1995) (Guerardel et al., 2001) (Britschgi et al., 2006) is shown as a dark oval. 


\section{Repression \\ Class I and II HDACs}

\section{-Independent}

-Dependent

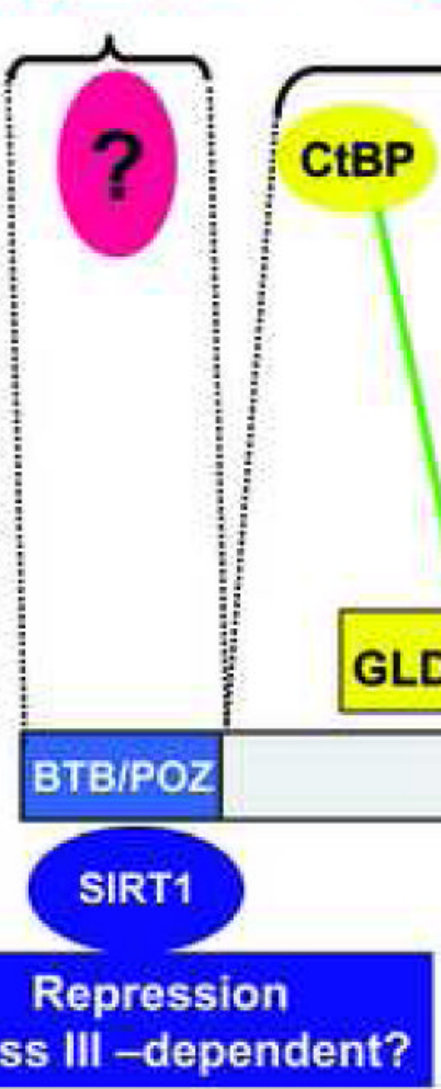

Figure 2. Domain organization of the human HIC1 protein

The two autonomous repression domains of HIC1, the BTB/POZ domain and the central region, are shown together with the known molecular mechanisms underlying their repression potential. Although HIC1 interacts with the class III deacetylase SIRT1 (Chen et al., 2005), its direct role in the BTB/POZ-mediated repression is not fully established. The co-repressor complex(es) involved in the TSA-insensitive repression potential of the BTB/POZ domain (Deltour et al., 1999) have still to be identified. The Central Region contains 4 short peptides motifs which have been phylogenetically conserved. The function of two of them has been deciphered. The GLDLSKK motif is a variant of the classical CtBP interacting domain (CID), the PLDLS motif, involved in the recruitment of the CtBP corepressor (Deltour et al., 2002) (Chinnadurai, 2007). The only invariant residue among CtBP interacting domains, Leucine 225 is highlighted since its mutation impairs the interaction between $\mathrm{HIC} 1$ and $\mathrm{CtBP}$ (Stankovic-Valentin et al., 2006). The Lysine K314 is contained within a MKHEP motif which is a SUMOylation/Acetylation switch motif (Stankovic-Valentin et al., 2007). The transcriptional repression potential of HIC1 is positively controlled by a complex between two types of deacetylases, SIRT1 and HDAC4. SIRT1 deacetylates HIC1 at lysine K314 whereas HDAC4 favors its SUMOylation through a mechanism still poorly understood (StankovicValentin et al., 2007). The corepressor(s) whose recruitment is positively regulated by HIC1 
SUMOylation as well as the CtBP-independent corepressors recruited by the central region are currently unknown (Stankovic-Valentin et al., 2006) (Stankovic-Valentin et al., 2007). $\mathrm{HIC} 1$ binds specifically to DNA through its $5 \mathrm{C}$-terminal Zinc fingers (ZF) domain that recognizes the consensus sequence 5 '- $\mathrm{C} /{ }_{\mathrm{G}} \mathrm{NG} / \mathrm{G}$ GGGCA $/ \mathrm{A} C \mathrm{C}-3^{\prime}$ centered on a GGCA core motif bound by Zinc fingers 3 and 4 (Pinte et al., 2004b). The HIC1 BTB/POZ domain negatively regulates the DNA-binding of the full-length protein to a single site whereas the oligomerization of the protein via this domain mediates cooperative DNA-binding to multiple sites (Pinte et al., 2004b). 